OPEN ACCESS

Edited by:

Pilar López-Larrubia,

Consejo Superior de Investigaciones

Cientificas (CSIC), Spain

Reviewed by:

Zhichao Li,

Chongqing West District Hospital,

China

Kavita Singh,

Massachusetts General Hospital and Harvard Medical School, United States

*Correspondence:

Nathalie Andre

nathalie.andre@univ-poitiers.fr

Specialty section:

This article was submitted to

Cancer Imaging and

Image-directed Interventions,

a section of the journal

Frontiers in Oncology

Received: 11 September 2021 Accepted: 08 November 2021

Published: 20 December 2021

Citation:

André N, Gastinger S and Rébillard A (2021) Chronic Fatique in Cancer, Brain Connectivity and Reluctance to Engage in Physical Activity: A Mini-Review.

Front. Oncol. 11:774347. doi: 10.3389/fonc.2021.774347

\section{Chronic Fatigue in Cancer, Brain Connectivity and Reluctance to Engage in Physical Activity: A Mini-Review}

\author{
Nathalie André ${ }^{1,2 *}$, Steven Gastinger ${ }^{3,4}$ and Amélie Rébillard ${ }^{3,5}$ \\ ${ }_{1}^{1}$ Research Centre on Cognition and Learning (UMR CNRS 7295), University of Poitiers, Sport Sciences Faculty, \\ Poitiers, France, ${ }^{2}$ Maison des Sciences de l'Homme et de la Société (USR CNRS 3565), Université de Poitiers, \\ Poitiers, France, ${ }^{3}$ M2S-EA7470, University of Rennes, Rennes, France, ${ }^{4}$ APCoSS - Institut de Formation en Education \\ Physique et en Sport (IFEPSA), UCO Angers, Angers, France, ${ }^{5}$ Institut Universitaire de France (IUF), Paris, France
}

A large amount of evidence shows that after a cancer diagnosis, patients significantly reduce their level of physical activity. Usually, this reduction is attributed to cancer-related fatigue. However, to our knowledge, no study has clearly demonstrated that fatigue alters effort-based decision-making in cancer. This mini-review aimed to provide evidence that chronic fatigue in cancer patients causes changes in brain connectivity that impact effortbased decision-making. Indeed, three patterns of activation to compensate for dysfunctional networks have been reported: greater variability in the executive network and hyperactivation in the executive network, which account for less efficient and costly processes in the frontal cortex, and reduced deactivation in the default mode network. Nevertheless, these activation patterns are also observed with other factors, such as anticipatory stressors (worry, rumination or sleep loss), that might also cause reluctance to engage in physical activity. Effort-based decision-making involving weighing costs against benefits and physical activity interventions should increase immediate benefits to facilitate engagement in effortful activities.

Keywords: chronic fatigue, immediate benefits, functional connectivity, physical activity, effort-based decision making, cost-benefit analysis

\section{INTRODUCTION}

Cancer-related fatigue (CRF) is one of the most common and distressing side effects and can persist for years after treatment has ended in otherwise healthy survivors (1). This feeling of fatigue is generally perceived as the main impediment to physical activity (PA), which requires physical and mental effort. Indeed, walking regularly, muscle-strengthening activities, maintaining intensity throughout a physical activity program and planning exercise for the following weeks are mentally and physically costly. Moreover, a general belief among cancer patients, family caregivers and some health professionals is that fatigue is recovered by rest rather than activity (2). Therefore, unsurprisingly, the literature on PA and CRF frequently reports that the level of PA after a cancer diagnosis or during cancer treatment is significantly reduced, all cancer combined [e.g (3-5)]. 
However, the special hallmark of fatigue in cancer is that it is not recovered by rest but rather by activity. Indeed, an increasing number of meta-analyses and systematic reviews report that PA is more effective than rest for reducing fatigue, suggesting a moderate effect $[$ e.g $(6,7)]$. Specifically, beneficial effects of exercise on fatigue have been observed in trials conducted with patients during and after treatment (8-10), indicating that resistance and moderate-to-high-intensity exercises can be helpful at different stages of the disease trajectory. During treatment, exercise may buffer treatment-related increases in fatigue, whereas exercise may reduce fatigue in patients after treatment completion $[$ e.g $(6,11)]$. In other words, PA allows maintenance of a baseline level of fatigue (generally measured after diagnosis) and faster recovery from treatment (8-10, 1217). However, exercise programs require effortful engagement, which may explain the low level of adherence and the high level of attrition observed in clinical trials (18-21).

If cancer patients are reluctant to engage in PA despite being aware of the long-term benefits of PA, something may be missing in our understanding of CRF and its role in effort-based decisionmaking regarding participation in PA (22-24). The decision to engage in PA relies on the computation of several costs of effort and expected benefits of PA $(25,26)$, and chronic fatigue might be a key aspect of unwillingness to expend any effort $(24,27,28)$. Chronic fatigue can hinder motivation or self-regulatory capacities, leading cancer patients to choose effortless activities such as rest rather than effortful activities such as PA.

An interesting opportunity to achieve substantial progress in PA-based interventions for fatigued cancer patients would be to examine brain connectivity and its effect on effort-based decision-making. Indeed, to date, concerns have focused on the role of inflammation in the development of CRF $(24,29-32)$, but its implication in the reluctance of cancer patients to engage in PA has not been established. Even if several factors can cause durable changes in brain functional connectivity (See Figure 1), we propose that brain connectivity dysfunction in case of chronic fatigue alters effort-based decision-making useful to engage in PA. This hypothesis has never been proposed.

Here, we demonstrate that CRF is associated with alterations in brain connectivity related to effort-based decision-making and can thus hinder attempts to engage in regular PA. Accordingly, we demonstrate that fatigue in cancer alters such brain connectivity by examining studies using functional magnetic resonance imaging (fMRI). The discussion section highlights that interventions targeting chronic fatigue in cancer should consider individual differences in lost or depleted inner resources rather than symptoms alone, as in previous cancer research. Clinical and interventional implications are then proposed.

\section{DEFINITION OF CHRONIC FATIGUE IN CANCER}

Although no definition of CRF has been established, the concept has been described. According to the National Comprehensive Cancer Network (33), CRF is described as "a distressing, persistent, subjective sense of physical, emotional, and/or cognitive tiredness or exhaustion related to cancer or cancer treatment that is not proportional to recent activity and interferes with functioning". Cancer-related fatigue should be distinguished from everyday fatigue, which can be easily recovered by rest. According to Bootsma et al. (34), CRF is chronic and should be considered a permanent symptom. Nevertheless, CRF is increasingly regarded as a multisymptom concept generally associated with physical and mental fatigue rather than a single symptom $(35,36)$. Thus, fatigue in cancer refers to a failure to initiate and/or sustain attentional tasks (mental fatigue) and physical activities (physical fatigue) requiring self-motivation (as opposed to external stimulation) in the absence of any clinically detectable motor weakness or dementia (37).

\section{BRAIN NETWORK AND FUNCTIONAL CONNECTIVITY IN CHRONIC FATIGUE}

\section{Three Large-Scale Brain Networks}

Deciding to practice regular PA according to recommendations requires efficient cognitive control and self-regulatory capacities. Neuroimaging studies analyzing resting-state functional connectivity have suggested the existence of at least three large-scale brain networks related to different aspects of highlevel cognitive functions and self-regulation (38-41), including the default-mode network (DMN), the central executive network $(\mathrm{CEN})$ and the salience network $(\mathrm{SN})$.

The DMN plays a key role in self-related processes, introspection, self-awareness, metacognition, prospective selfprojection, and autobiographic memory recall (42-47) and is deactivated during cognitively demanding tasks (48-51). The DMN thus allows the construction of mental models or simulations having an adaptive function and facilitating future behavior. These simulations therefore represent a means of anticipating and evaluating future events to react to them as best as possible, to build a stable identity over time and to adapt to the social world. The DMN mainly includes the ventromedial prefrontal cortex, the posterior cingulate cortex, the precuneus, the retrosplenial cortex, the lateral parietal lobes and the medial temporal lobes (52).

The CEN and SN are activated during a wide variety of tasks $(40,49)$. The CEN $(36,53)$, a frontoparietal cognitive system that controls and manages executive functions, contributes to executive control, particularly by maintaining and updating information in working memory, sustained attention, response selection, and response suppression. The $\mathrm{CEN}$ is also responsible for decision-making and problem solving in the pursuit of goaldirected behavior (41). The CEN is mainly anchored in the dorsolateral prefrontal cortex, the ventrolateral prefrontal cortex, the dorsomedial prefrontal cortex, and the lateral posterior parietal cortex $(40,53,54)$.

The SN, a cingulated frontal operculum system, is involved in identifying the most homeostatically relevant signals among a myriad of internal and extrapersonal stimuli to make decisions $(40,55)$, 


\section{FACTORS}

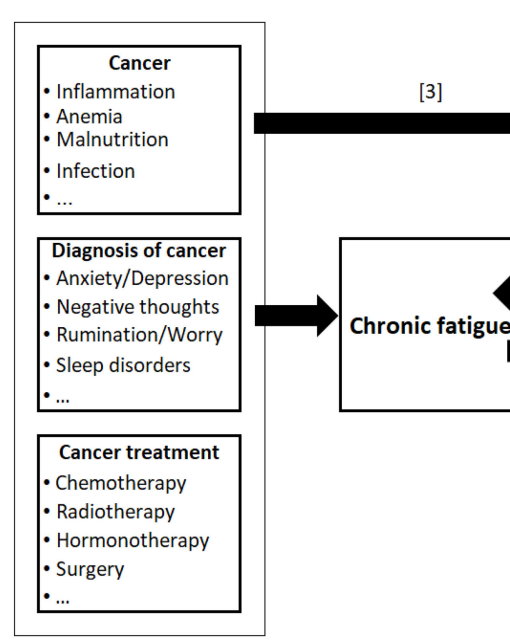

BRAIN CONNECTIVITY

SELF-REGULATORY CAPACITIES

FIGURE 1 | Relationships between chronic fatigue and brain connectivity. The figure represents the links between cancer-related factors and effort-based decisionmaking to practice PA. The causal relationship between chronic fatigue and brain connectivity (BC) can be of three types: [1] fatigue causes changes in BC; [2] the change in BC causes fatigue; [1\&2] a bidirectional relationship. Moreover, factors such as cancer itself, diagnosis and treatment of cancer may directly alter the brain connectivity [3].

manage errors and conflicts $(56,57)$, and ensure autonomic control $(58,59)$. The salience network is a large functional neuronal network involved in the generation of the effort signal (22). This system mainly consists of the orbital frontoinsular cortex, the dorsal anterior cingulated cortex (dACC), the anterior insula, and the superior temporal gyrus (40). Uddin et al. (60) reported that during task performance, the salience network coordinates and controls deactivation of the DMN and activation of the CEN.

\section{Functional Connectivity in Chronic Fatigue}

Several studies using brain imaging in humans confirm that the within-network connectivity of the $\mathrm{SN}$ is weakened in the case of chronic fatigue syndrome/myalgic encephalomyelitis and depression (61-66). In addition, these disorders are associated with persistent weakened connectivity between the SN and CEN and persistent strengthened connectivity between the SN and DMN (66-68). This deterioration in effort capacity results in a persistent weakening of SN connectivity through negative longterm structural changes requiring several weeks or months to occur and a brain connectivity less coordinated across area of the DMN $(69,70)$. The following section provides evidence that altered brain connectivity in chronic fatigue in cancer hinders effort-based decision-making.

\section{TASK-RELATED FUNCTIONAL CONNECTIVITY AND CHRONIC FATIGUE IN CANCER}

The question is whether chronic fatigue in cancer alters functional brain connectivity implied in effort-based decision- making; if so, a new mechanism related to brain connectivity explaining disengagement from PA by cancer patients warrants investigation. Based on six studies examining the relationship between chronic fatigue and task-related fMRI (71-76), three patterns of connectivity have been identified as plausible neural biomarkers of chronic fatigue in cancer patients (See Table 1).

\section{Spatial Variance in the Executive Network}

First, using verbal working memory task-related fMRI, Askren et al. (71) and Jung et al. (72) compared women with breast cancer treated with chemotherapy to women who received no adjuvant treatment. They both reported increased variance in the BOLD signal in the executive network in women with adjuvant treatment. Typically, the neural response in healthy people is lower spatial variance in executive network activity during task activation, reflecting strong attentional engagement. Interestingly, this greater spatial variance was still higher in the posttreatment chemotherapy group than in the nontreatment group in both studies. In contrast, this change in variance predicted posttreatment fatigue only in the study by Askren et al. (71). Engagement of the executive (or frontoparietal) network in the case of chemotherapy was found to be more variable/idiosyncratic (77) in chemotherapy-treated women. Generally, this pattern of spatial activation is often considered a compensatory mechanism such that when a given neural system is dysfunctional, other systems (regions/networks) may become engaged in an attempt to support task performance. However, this variability consumes more biological resources and is costly.

\section{Hyperactivation of the Executive Network}

In addition to the variability in the executive network, Menning et al. $(74,75)$ and De Dreu et al. $(73)$ reported hyperactivation in 
the CEN using task-related fMRI (verbal working memory and planning tasks, respectively). This hyperactivation was mainly observed before and during treatment but not posttreatment. Pretreatment hyperactivity was higher in women awaiting chemotherapy than in those without chemotherapy. This pattern of connectivity was explained by fatigue only in the studies by Menning et al. $(74,75)$. In these three studies, chemotherapy-treated women had increased brain activation in the dorsolateral prefrontal cortex during the tasks, suggesting that the hub of the executive network may be overengaged during task processing. The hyperactivation in the CEN can be explained by increased recruitment of expanded neural circuitry to support structural functioning (78). Here, again, this pattern may be associated with a compensatory mechanism. Interestingly, CEN hyperactivation decreased over time in the chemotherapy group (i.e., in the posttreatment group), with increasing task loads corresponding to more difficulties sustaining mental effort.

These results suggest that during a task targeting executive functions, women with breast cancer must expend more effort due to greater inner resource depletion. This widespread activation may lead to an increased demand for neural resources such as oxygen and glucose, in turn leading to fatigue (79). Fatigue and lower performance have been associated with increased brain activity while performing a high-effort cognitive task (80-82). Severe fatigue has been hypothesized to consume a significant amount of attentional resources in terms of recruiting additional brain regions for cognitive compensation to perform better in tasks depending on the degree of mental effort (82).

\section{Reduced Deactivation of the DMN}

A third pattern of connectivity emerged in three studies (73, 75, 76) on brain tumors and breast cancer during treatment and before chemotherapy. They all reported a reduced capacity to inhibit DMN activation, which was correlated with measures of fatigue. Given the role of the DMN in disrupting attentional and engagement processes (38), failure to suppress DMN regions during tasks should be related to decreased attention and/or motivation toward the task. Nevertheless, within the DMN, hyperactivation was also observed on resting-state fMRI (62). Chemotherapy can induce white matter disruption (83) and a reduction in gray matter density in several brain regions, including the DMN (84). Specifically, the precuneus, cingulate, lateral parietal cortex, medial frontal gyrus, cerebellum and hippocampus appear to be the structures most impacted by cancer treatments. Since the DMN is thought to be involved in contemplation, remembering, and rumination, the authors suggested that enhanced connectivity between the DMN and the frontal gyrus may be related to more cogitation (62) and partially responsible for mental fatigue.

This failure to suppress default mode activity during tasks has been linked to decreased activity in task-related regions leading to attentional lapses and decreases in performance (85-87). This disengagement of brain regions associated with mental effort (higher spatial variance) favoring of brain regions linked to resting activity (the default network) might be intended to conserve mental resources for the maintenance of engagement in the task (88).

These results show that the hypothesized pattern of connectivity is partly corroborated, that is, a reduced capacity of the $\mathrm{SN}$ to deactivate the DMN. In contrast, no clear weakening of the connectivity between the SN and the CEN has been reported. Nevertheless, the increasing activation of the CEN may be associated with a compensatory mechanism. Finally, reduced connectivity in the executive network is associated with fatigue and task performance failure after chemotherapy completion.

\section{DISCUSSION}

This mini-review aimed to explore the relationship between chronic fatigue in cancer and functional connectivity patterns during task-related fMRI. Our literature review suggests that effort-based decision-making may be altered by the changes in brain connectivity, specifically within DMN and between DMN and other networks. These results do not provide information on the direction of the relationships between chronic fatigue and network connectivity. Nevertheless, the direction of this relationship between these two variables can be conceived in three ways: a unilateral effect of chronic fatigue on network connectivity, a unilateral effect of changes in connectivity that induce chronic fatigue, or a bidirectional relationship between these two variables.

Chronic fatigue might result in difficulty concentrating (i.e., a symptom), which is explained by different brain activation patterns. First, the pattern of chronic fatigue without treatment or before treatment resembles alterations caused by anticipatory stress. Andreotti et al. (89) emphasized neurocognitive alterations in cancer populations independent of treatments, supporting the role of the allostatic load induced by recurrent and continuous stressors such as cancer diagnoses, negative recurrent thoughts, and chronic pain but also by remembering novel medication regimens and medical appointments. The allostatic system includes two established large-scale brain networks containing most of the limbic cortices: the SN and the DMN. According to the authors, the allostatic mechanisms are not tuned to help an individual respond effectively to prolonged and repetitive psychological stressors that lead to overactivity and dysregulation of the allostatic network. Interestingly, Brosschot et al. (90) proposed that this prolonged activation can also be generated by prolonged active cognitive representations of stressors, also called perseverative cognition, and that it occurs by phenomena such as worry, rumination and anticipatory stress, such as a lack of sleep.

The dysfunctional activation of the executive network (i.e., greater spatial variance and hyperactivation of the executive network) validates the ability of cancer patients to use compensatory mechanisms to successfully engage in effortful activities but at the cost of significant effort. This capacity is reduced during treatment and at the end of the treatment, suggesting that the toxicity of the molecules during chemotherapy modifies the structure of the brain at the gray 
TABLE 1 | Characteristics of included studies.

\begin{tabular}{|c|c|c|c|c|c|c|}
\hline References & Population & $\begin{array}{l}\text { - Design } \\
\text { - Type of cancer } \\
\text { - Moment of the } \\
\text { treatment }\end{array}$ & $\begin{array}{l}\text { Measure of } \\
\text { fatigue }\end{array}$ & $\begin{array}{l}\text { fMRI } \\
\text { scanner } \\
\text { task }\end{array}$ & $\begin{array}{c}\text { Patterns of brain } \\
\text { functional connectivity }\end{array}$ & Relationship with chronic fatigue \\
\hline $\begin{array}{l}\text { Churchill } \\
\text { et al. (76) }\end{array}$ & $\begin{array}{l}28 \text { women } \\
\text { in pre-CHE } \\
37 \text { women } \\
\text { pre-RAD } \\
32 \text { healthy } \\
\text { control } \\
\text { N/A }\end{array}$ & $\begin{array}{l}\text { - } \text { Cross-sectional } \\
\text { - Breast cancer } \\
\text { (24 to } 34 \text { days after } \\
\text { surgery) } \\
\text { - Pre-treatment }\end{array}$ & $\begin{array}{l}\text { The Functional } \\
\text { Assessment of } \\
\text { Chronic Illness } \\
\text { Therapy - } \\
\text { Fatigue (FACIT-F) }\end{array}$ & $\begin{array}{l}\text { Verbal } \\
\text { working } \\
\text { memory } \\
\text { task }\end{array}$ & $\begin{array}{l}\uparrow \text { of the activation in posterior cingulate } \\
\text { cortex and precuneus activation and } \downarrow \text { in } \\
\text { Hurst exponent (parietal lobes and } \\
\text { thalamus) in high distress profile } \\
\text { (patients with sleep problems and } \\
\text { worry). }\end{array}$ & $\begin{array}{l}\text { No direct measure of fatigue but the } \\
\text { physical distress (fatigue and sleep } \\
\text { disorders) is correlated with the } \\
\text { decrease in Hurst exponent. }\end{array}$ \\
\hline $\begin{array}{l}\text { Askren } \\
\text { et al. (71) }\end{array}$ & $\begin{array}{l}28 \text { women } \\
\text { with } \mathrm{CHE} \\
37 \text { women } \\
\text { non } \mathrm{CHE} \\
32 \text { healthy } \\
\text { control } \\
51 \text { years } \\
\text { old }\end{array}$ & $\begin{array}{l}\text { - } \text { Cross-sectional } \\
\text { - Breast cancer } \\
\text { - During treatment }\end{array}$ & $\begin{array}{l}\text { The Functional } \\
\text { Assessment of } \\
\text { Chronic Illness } \\
\text { Therapy - Fatigue } \\
\text { (FACIT-F) }\end{array}$ & $\begin{array}{l}\text { Verbal } \\
\text { working } \\
\text { memory } \\
\text { task }\end{array}$ & $\begin{array}{l}\uparrow \text { spatial variance in executive network } \\
\text { (left and right frontal cortex, anterior } \\
\text { cingulate, left and right parietal cortex) } \\
\text { for the CHE groups compared to the } \\
\text { two other groups. }\end{array}$ & $\begin{array}{l}\text { The spatial variance in executive } \\
\text { network predicts post-treatment fatigue } \\
\text { severity and cognitive complaints for } \\
\text { CHE group }\end{array}$ \\
\hline $\begin{array}{l}\text { Menning } \\
\text { et al. (74) }\end{array}$ & $\begin{array}{l}32 \text { women } \\
\text { in pre-CHE } \\
33 \text { women } \\
\text { pre-non } \\
\text { CHE } \\
38 \text { healthy } \\
\text { control } \\
50.9 \text { years } \\
\text { old }\end{array}$ & $\begin{array}{l}\text { - Cross-sectional } \\
\text { - Breast cancer } \\
\text { - Pre-treatment }\end{array}$ & $\begin{array}{l}\text { Fatigue subscale } \\
\text { of the EORTC } \\
\text { QLQ-C30 } \\
\text { Fatigue subscale } \\
\text { of the POMS }\end{array}$ & $\begin{array}{l}\text { - Planning } \\
\text { test (Tower } \\
\text { of London) } \\
\text { - Paired } \\
\text { Associates } \\
\text { memory } \\
\text { task }\end{array}$ & $\begin{array}{l}\text { Pre-CHE vs Control groups: } \\
\text { hyperactivation of the dorsomedial } \\
\text { prefrontal cortex extending into the } \\
\text { DLPFC with increasing task difficulty for } \\
\text { pre-CHE. } \\
\text { Pre-non CHE vs Control groups: } \\
\text { subthreshold hyperactivation of the } \\
\text { dorsomedial prefrontal cortex extending } \\
\text { into the DLPFC for pre-non CHE. }\end{array}$ & $\begin{array}{l}\text { Significant correlation between fatigue } \\
\text { and the activation of the dorsomedial } \\
\text { prefrontal cortex on the planning task } \\
\text { across all groups. }\end{array}$ \\
\hline $\begin{array}{l}\text { Menning } \\
\text { et al. (75) }\end{array}$ & $\begin{array}{l}28 \text { women } \\
\text { with } \mathrm{CHE} \\
\text { (with or } \\
\text { without } \\
\text { endocrine } \\
\text { treatment) } \\
24 \text { women } \\
\text { non CHE } \\
31 \text { healthy } \\
\text { control } \\
50.6 \text { years } \\
\text { old }\end{array}$ & $\begin{array}{l}\text { - } \text { Cross-sectional } \\
\text { - Breast cancer } \\
\text { - } \text { During treatment }\end{array}$ & $\begin{array}{l}\text { Fatigue subscale } \\
\text { of the EORTC } \\
\text { QLQ-C30 }\end{array}$ & $\begin{array}{l}\text { - Planning } \\
\text { test (Tower } \\
\text { of London) } \\
\text { - Paired } \\
\text { Associates } \\
\text { memory } \\
\text { task }\end{array}$ & $\begin{array}{l}\text { CHE vs non CHE: } \uparrow \text { of the activation in } \\
\text { the bilateral inferior parietal cortex and } \\
\text { the precuneus extending into the } \\
\text { superior parietal cortex with increasing } \\
\text { task load in the CHE compared to the } \\
\text { non CHE group. } \\
\text { Non CHE vs Control: } \downarrow \text { over time of the } \\
\text { activation in the right inferior parietal } \\
\text { cortex in non CHE compared to Control } \\
\text { group with increasing task load. }\end{array}$ & $\begin{array}{l}\text { The non CHE group showed a } \\
\text { correlation between baseline fatigue } \\
\text { and change in BOLD signal in the right } \\
\text { inferior parietal cortex during the } \\
\text { planning task. } \\
\text { A negative correlation was found } \\
\text { between change in fatigue and change } \\
\text { in BOLD signal in the right inferior } \\
\text { parietal cortex in the non CHE group. }\end{array}$ \\
\hline $\begin{array}{l}\text { Jung et al. } \\
(72)\end{array}$ & $\begin{array}{l}28 \text { women } \\
\text { with } \mathrm{CHE} \\
34 \text { women } \\
\text { non } \mathrm{CHE} \\
30 \text { control } \\
\text { group } \\
51.58 \text { years } \\
\text { old }\end{array}$ & $\begin{array}{l}\text { - Longitudinal } \\
\text { - } \quad 4 \text { moments: } 1 \\
\text { month post-surgery; } \\
\text { before any planned } \\
\text { adjuvant; five } \\
\text { months following } \\
\text { baseline; } 1 \text { year } \\
\text { post-baseline }\end{array}$ & $\begin{array}{l}\text { Breast Cancer } \\
\text { Prevention Trial } \\
\text { Symptom Scales } \\
\text { (BCPTSS) }\end{array}$ & $\begin{array}{l}\text { Verbal } \\
\text { working } \\
\text { memory } \\
\text { task }\end{array}$ & $\begin{array}{l}\text { From baseline to Month } 12: ~ \uparrow \text { spatial } \\
\text { variance in the executive network during } \\
\text { task activation for the } \mathrm{CHE} \text { group } \\
\text { compared to the other groups. In } \\
\text { healthy patient, the variance of the fMRI } \\
\text { signal decrease during task activation } \\
\text { (habituation). }\end{array}$ & $\begin{array}{l}\text { No direct measures of fatigue but } \\
\text { persistent cognitive complaints are } \\
\text { correlated with physical symptom } \\
\text { severity and worry regardless of } \\
\text { treatment. }\end{array}$ \\
\hline $\begin{array}{l}\text { De Dreu } \\
\text { et al. (73) }\end{array}$ & $\begin{array}{l}23 \\
\text { participants } \\
\text { with } \\
\text { meningioma } \\
21 \text { low } \\
\text { grade } \\
\text { glioma } \\
19 \text { high } \\
\text { grade } \\
\text { glioma } \\
49.2 \text { years } \\
\text { old }\end{array}$ & $\begin{array}{l}\text { - } \text { Cross-sectional } \\
\text { - } \text { Brain tumor } \\
\text { - After surgery }\end{array}$ & $\begin{array}{l}\text { Multidimensional } \\
\text { fatigue inventory } \\
\text { (MFI-20) }\end{array}$ & $\begin{array}{l}\text { Task on } \\
\text { attention } \\
\text { (analysis } \\
\text { during } \\
\text { phasic } \\
\text { alertness) }\end{array}$ & $\begin{array}{l}\downarrow \text { of the deactivation of the DMN (left } \\
\text { and right lingual cortex; left and right } \\
\text { cuneus; right precuneus) for the three } \\
\text { groups. }\end{array}$ & $\begin{array}{l}\text { The total score of fatigue do not } \\
\text { correlate with the signal change in the } \\
\text { CEN during phasic alertness while total } \\
\text { score of fatigue, but also general, } \\
\text { physical and mental fatigue correlate } \\
\text { with the signal change in the DMN for } \\
\text { each group. }\end{array}$ \\
\hline
\end{tabular}

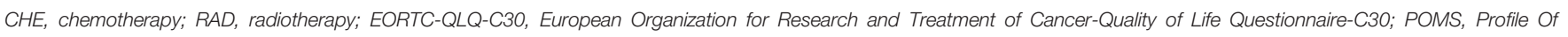
Mood State. 
and white matter levels, which modifies functional brain connectivity. Thus, cancer patients are no longer be able to compensate.

In summary, chronic fatigue leads to the use of compensatory mechanisms that are cognitively costly for cancer patients, which might impact the decision to engage in or maintain PA. These mechanisms have been reported as patterns of adaptation of brain activity in studies examining the functional connectivity in several chronic diseases such as chronic fatigue syndrome (69) and multiple sclerosis (91). However, this hyperactivation is not always correlated with the level of fatigue. In contrast, the reduced deactivation of the DMN in the three studies examined appears to correlate with the level of fatigue. According to Shan et al. (69), deficits in DMN could be energy expensive and may contribute to or cause the fatigue. This abnormal activity of DMN might be a marker of fatigue in cancer.

Three perspectives can be proposed. First, PA interventions should increase immediate benefits to reduce the imbalance between cost (chronic fatigue) and benefits (general wellbeing) and facilitate engagement in effortful activities such as PA. Interestingly, behavioral change techniques have been reported

\section{REFERENCES}

1. Cho D, Park CL. Barriers to Physical Activity and Healthy Diet Among Breast Cancer Survivors: A Multilevel Perspective. Eur J Cancer Care (2018) 27: e12772. doi: 10.1111/ecc.12772

2. Lucia A, Earnest C, Pérez M. Cancer-Related Fatigue: Can Exercise Physiology Assist Oncologists? Lancet Oncol (2003) 4:616-25. doi: 10.1016/ S1470-2045(03)01221-X

3. Fassier P, Zelek L, Partula V, Srour B, Bachmann P, Touillaud M, et al. Variations of Physical Activity and Sedentary Behavior Between Before and After Cancer Diagnosis. Medicine (2016) 95:40. doi: 10.1097/MD. 0000000000004629

4. Hackshaw-McGeagh LE, Perry RE, Leach VA, Qandil S, Jeffreys M, Martin RM, et al. A Systematic Review of Dietary, Nutritional, and Physical Activity Interventions for the Prevention of Prostate Cancer Progression and Mortality. Cancer Causes Control (2015) 26:1521-50. doi: 10.1007/s10552-015-0659-4

5. Robertson MC, Lyons EJ, Song J, Cox-Martin M, Li Y, Green CE, et al. Change in Physical Activity and Quality of Life in Endometrial Cancer Survivors Receiving a Physical Activity Intervention. Health Qual Life Outcomes (2019) 17:91. doi: 10.1186/s12955-019-1154-5

6. Cramp F, Byron-Daniel J. Exercise for the Management of Cancer-Related Fatigue in Adults. Cochrane Database Syst Rev (2008) Issue 2. Art. No: CD006145. doi: 10.1002/14651858.CD006145.pub2

7. Berger AM, Mooney K, Alvarez-Perez A, Breitbart WS, Carpenter KM, Cella D, et al. Cancer-Related Fatigue, Version 2. J Natl Compr Cancer Network (2015) 13:1012-39. doi: 10.6004/jnccn.2015.0122

8. Hu Q, Zhao D. Effects of Resistance Exercise on Complications, CancerRelated Fatigue and Quality of Life in Nasopharyngeal Carcinoma Patients Undergoing Chemoradiotherapy: A Randomised Controlled Trial. Eur J Cancer Care (2020) 00:e13355. doi: 10.1111/ecc.13355

9. Stan DL, Croghan KA, Croghan IT, Jenkins SM, Sutherland SJ, Cheville AL, et al. Randomized Pilot Trial of Yoga Versus Strengthening Exercises in Breast Cancer Survivors With Cancer-Related Fatigue. Support Care Cancer (2016) 24:4005-15. doi: 10.1007/s00520-016-3233-z

10. Kampshoff CS, Chinapaw MJM, Brug J, Twisk JWR, Schep G, Nijziel MR, et al. Randomized Controlled Trial of the Effects of High Intensity and Lowto-Moderate Intensity Exercise on Physical Fitness and Fatigue in Cancer Survivors: Results of the Resistance and Endurance Exercise After to be helpful interventions to increase immediate benefits such as 'social rewards', 'prompts', 'nonspecific rewards' and 'graded tasks' in cancer $(92,93)$. Second, exploring other regions of interest, such as the basal ganglia, may be more productive to understand the role of motivation and reward in effort-based decision-making among fatigued cancer patients (94). Decreased activation in the basal ganglia in chronic fatigue syndrome has been demonstrated to be correlated with increased mental fatigue, general fatigue and reduced PA (95). Third, these patterns of impaired brain connectivity in the case of chronic fatigue can also be observed with perseverative cognition (89), including worry, rumination and anticipatory stress, such as sleep disturbance. These three perspectives should be examined further.

\section{AUTHOR CONTRIBUTIONS}

NA, SG, and AR conceived the plan of the article and were engaged in the literature review process. NA wrote the article. NA, SG, and AR reread the last version of the article. All authors contributed to the article and approved the submitted version.
ChemoTherapy (REACT) Study. BMC Med (2015) 13:275. doi: 10.1186/ s12916-015-0513-2

11. Courneya KS, Segal RJ, Mackey JR, Gelmon K, Reid RD, Friedenreich CM, et al. Effects of Aerobic and Resistance Exercise in Breast Cancer Patients Receiving Adjuvant Chemotherapy: A Multicenter Randomised Controlled Trial. J Clin Oncol (2007) 25:4396-404. doi: 10.1200/JCO.2006.08.2024

12. Zhou W, Wan Y-H, Chen Q, Qiu Y-R, Luo X-M. Effects of Tai Chi Exercise on Cancer-Related Fatigue in Patients With Nasopharyngeal Carcinoma Undergoing Chemoradiotherapy: A Randomized Controlled Trial. J Pain Symptom Manage (2018) 55:737-44. doi: 10.1016/j.jpainsymman.2017.10.021

13. Zhang L-L, Wang S-Z, Chen H-L, Yuan A-Z. Tai Chi Exercise for CancerRelated Fatigue in Patients With Lung Cancer Undergoing Chemotherapy: A Randomized Controlled Trial. J Pain Symptom Manage (2016) 51:504-11. doi: 10.1016/j.jpainsymman.2015.11.020

14. Travier N, Velthuis MJ, Steins Bisschop CN, van den Buijs B, Monninkhof EM, Backx F, et al. Effects of an 18-Week Exercise Programme Started Early During Breast Cancer Treatment: A Randomised Controlled Trial. BMC Med (2015) 13:121. doi: 10.1186/s12916-015-0362-z

15. Witlox L, Hiensch AE, Velthuis MJ, Steins Bisschop CN, Los M, Erdkamp FL, et al. Four-Year Effects of Exercise on Fatigue and Physical Activity in Patients With Cancer. BMC Med (2018) 16:86. doi: 10.1186/s12916-018-1075-x

16. Van Waart H, Stuiver MM, van Harten WH, Geleijn E, Kieffer JM, Buffart LM, et al. Effect of Low Intensity Physical Activity and Moderate- to HighIntensity Physical Exercise During Adjuvant Chemotherapy on Physical Fitness, Fatigue, and Chemotherapy Completion Rates: Results of the Paces Randomized Clinical Trial. J Clin Oncol (2015) 33:1918-27. doi: 10.1200/ JCO.2014.59.1081

17. Jong MC, Boers I, Schouten van der Velden AP, van der Meij S, Göker E, Timmer-Bonte ANJH, et al. A Randomized Study of Yoga for Fatigue and Quality of Life in Women With Breast Cancer Undergoing (Neo) Adjuvant Chemotherapy. J Altern Complement Med (2018) 24(9-10):942-953. doi: $10.1089 / \mathrm{acm} .2018 .0191$

18. Sheill G, Guinan E, Brady L, Hevey D, Hussey J. Exercise Interventions for Patients With Advanced Cancer: A Systematic Review of Recruitment, Attrition, and Exercise Adherence Rates. Palliative Support Care (2019) 17:686-96. doi: 10.1017/S1478951519000312

19. Van Vulpen JK, Sweegers MG, Peeters PHM, Courneya KS, Newton RU, Aaronson RK, et al. Moderators of Exercise Effects on Cancer-Related Fatigue: 
A Meta-Analysis of Individual Patient Data. Med Sci Sports Exercise (2020) 52:303-14. doi: 10.1249/MSS.0000000000002154

20. Turner RR, Steed L, Quirk H, Greasley RU, Saxton JM, Taylor SJ, et al. Interventions for Promoting Habitual Exercise in People Living With and Beyond Cancer. Cochrane Database Syst Rev (2018) 9:CD010192. doi: 10.1002/14651858.CD010192.pub3

21. Ormel HL, van der Schoot GGF, Sluiter WJ, Jalving M, Gietema JA, Walenkamp AME. Predictors of Adherence to Exercise Interventions During and After Cancer Treatment: A Systematic Review. Psycho-Oncology (2018) 27:713-24. doi: 10.1002/pon.4612

22. André N, Audiffren M, Baumeister FR. An Integrative Model of Effortful Control. Front Syst Neurosci (2019) 13:79. doi: 10.3389/fnsys.2019.00079

23. Shenhav A, Musslick S, Lieder L, Kool W, Griffiths TL, Cohen JD, et al. Toward a Rational and Mechanistic Account of Mental Effort. Annu Rev Neurosci (2017) 40:99-124. doi: 10.1146/annurev-neuro-072116-031526

24. Lacourt TE, Vichaya EG, Chiu GS, Dantzer R, Heijnen CJ. The High Costs of Low-Grade Inflammation: Persistent Fatigue as a Consequence of Reduced Cellular-Energy Availability and Non-Adaptive Energy Expenditure. Front Behav Neurosci (2018) 12:78. doi: 10.3389/fnbeh.2018.00078

25. Bailey MR, Simpson EH, Balsam PD. Neural Substrates Underlying Effort, Time, and Risk-Based Decision Making in Motivated Behavior. Neurobiol Learn Memory (2016) 133:233-56. doi: 10.1016/j.nlm.2016.07.015

26. Walton ME, Kennerley SW, Bannerman DM, Phillips PEM, Rushworth MFS. Weighing Up the Benefits of Work: Behavioral and Neural Analyses of EffortRelated Decision Making. Neural Network (2006) 19:1302-14. doi: 10.1016/ j.neunet.2006.03.005

27. Massar SAA, Csathó Á, Van der Linden D. Quantifying the Motivational Effects of Cognitive Fatigue Through Effort-Based Decision Making. Front Psychol (2018) 9:843. doi: 10.3389/fpsyg.2018.00843

28. van der Linden D. The Urge to Stop: The Cognitive and Biological Nature of Acute Mental Fatigue. In: PL Ackerman, editor. Cognitive Fatigue: Multidisciplinary Perspectives on Current Research and Future Applications, 1st Edn. Washington, DC: American Psychological Association (2011). p. 149-64.

29. Bower JE. Cancer-Related Fatigue: Links With Inflammation in Cancer Patients and Survivors. Brain Behav Immun (2007) 21:863-71. doi: 10.1016/ j.bbi.2007.03.013

30. Bower JE, Lamkin DM. Inflammation and Cancer-Related Fatigue: Mechanisms, Contributing Factors, and Treatment Implications. Brain Behav Immun (2013) 30:S48-57. doi: 10.1016/j.bbi.2012.06.011

31. Bower JE. The Role of Neuro-Immune Interactions in Cancer-Related Fatigue: Biobehavioral Risk Factors and Mechanisms. Cancer (2019) 125:353-64. doi: $10.1002 /$ cncr. 31790

32. Karshikoff B, Sundelin T, Lasselin J. Role of Inflammation in Human Fatigue: Relevance of Multidimensional Assessments and Potential Neuronal Mechanisms. Front Immunol (2017) 8:21. doi: 10.3389/fimmu.2017.00021

33. National Comprehensive Cancer Network. Clinical Practice Guidelines in Oncology. In: Cancer-Related Fatigue Version 2 Plymouth Meeting, PA 19462. (2019). Available at: www.nccn.org.

34. Bootsma TI, Schellekens MPJ, van Woezik RAM, van der Lee ML, Slatman J. Experiencing and Responding to Chronic Cancer-Related Fatigue:A MetaEthnography of Qualitative Research. Psycho-Oncology (2019) 29:1-10. doi: $10.1002 /$ pon. 5213

35. de Raaf PJ, de Klerk C, Timman R, Hinz A, van der Rijt CCD. Differences in Fatigue Experiences Among Patients With Advanced Cancer, Cancer Survivors, and the General Population. J Pain Symptom Manage (2012) 44:823-30. doi: 10.1016/j.jpainsymman.2011.12.279

36. de Raaf PJ, de Klerk C, van der Rijt CCD. Elucidating the Behavior of Physical Fatigue and Mental Fatigue in Cancer Patients: A Review of the Literature. Psycho-Oncology (2013) 22:1919-29. doi: 10.1002/pon.3225

37. Chaudhuri A, Behan PO. Fatigue and Basal Ganglia. J Neurol Sci (2000) 179:34-42. doi: 10.1016/S0022-510X(00)00411-1

38. Greicius MD, Menon V. Default-Mode Activity During a Passive Sensory Task: Uncoupled From Deactivation But Impacting Activation. J Cogn Neurosci (2004) 16:1484-1492. doi: 10.1162/0898929042568532

39. Fox MD, Snyder AZ, Vincent JL, Corbetta M, Van Essen DC, Raichle ME, et al. The Human Brain Is Intrinsically Organized Into Dynamic, Anticorrelated Functional Networks. Proc Natl Acad (2005) 102:9673-8. doi: $10.1073 /$ pnas.0504136102
40. Seeley WW, Menon V, Schatzberg AF, Keller J, Glover GH, Kenna H, et al. Dissociable Intrinsic Connectivity Networks for Salience Processing and Executive Control. J Neurosci (2007) 27:2349-56. doi: 10.1523/jneurosci.5587-06.2007

41. Menon V. Large-Scale Brain Networks and Psychopathology: A Unifying Triple Network Model. Trends Cogn Sci (2011) 15:483-506. doi: 10.1016/ j.tics.2011.08.003

42. Gusnard DA, Akbudak E, Shulman GL, Raichle ME. Medial Prefrontal Cortex and Self-Referential Mental Activity: Relation to a Default Mode of Brain Function. Proc Natl Acad Sci USA (2001) 98:4259-65. doi: 10.1073/ pnas.071043098

43. Buckner RL, Carroll DC. Self-Projection and the Brain. Trends Cogn Sci (2007) 11:49-57. doi: 10.1016/j.tics.2006.11.004

44. Spreng RN, Grady CL. Patterns of Brain Activity Supporting Autobiographical Memory, Prospection, and Theory of Mind, and Their Relationship to the Default Mode Network. J Cogn Neurosci (2010) 22:111223. doi: $10.1162 /$ jocn.2009.21282

45. Salomon R, Levy DR, Malach R. Deconstructing the Default: Cortical Subdivision of the Default Mode/Intrinsic System During Self-Related Processing. Hum Brain Mapp (2014) 35:1491-502. doi: 10.1002/hbm.22268

46. Davey CG, Pujol J, Harrison BJ. Mapping the Self in the Brain's Default Mode Network. NeuroImage (2016) 132:390-7. doi: 10.1016/j.neuroimage.2016.02.022

47. Lou HC, Changeux JP, Rosenstand A. Towards a Cognitive Neuroscience of Self-Awareness. Neurosci Biobehav Rev (2017) 83:765-73. doi: 10.1016/ j.neubiorev.2016.04.004

48. Shulman GL, Fiez JA, Corbetta M, Buckner RL, Miezin FM, Raichle ME, et al. Common Blood Flow Changes Across Visual Tasks: II. Decreases in Cerebral Cortex. J Cogn Neurosci (1997) 9:648-63. doi: 10.1162/jocn.1997.9.5.648

49. Binder JR, Frost JA, Hammeke TA, Bellgowan PSF, Rao SM, Cox RW. Conceptual Processing During the Conscious Resting State: A Functional MRI Study. J Cogn Neurosci (1999) 11:80-93. doi: 10.1162/089892999563265

50. Mazoyer B, Zago L, Mellet E, Bricogne S, Etard O, Houdé O, et al. Cortical Networks for Working Memory and Executive Functions Sustain the Conscious Resting State in Man. Brain Res Bull (2001) 54:287-98. doi: 10.1016/s0361-9230(00)00437-8

51. McKiernan KA, Kaufman JN, Kucera-Thompson J, Binder JR. A Parametric Manipulation of Factors Affecting Task-Induced Deactivation in Functional Neuroimaging. J Cogn Neurosci (2003) 15:394-408. doi: 10.1162/ 089892903321593117

52. Gusnard DA, Raichle ME. Searching for a Baseline: Functional Imaging and the Resting Human Brain. Nat Rev Neurosci (2001) 2:685-94. doi: 10.1038/ 35094500

53. Dosenbach NUF, Fair DA, Cohen AL, Schlaggar BL, Petersen SE. A DualNetworks Architecture of Top-Down Control. Trends Cogn Sci (2008) 12:99105. doi: 10.1016/j.tics.2008.01.001

54. Borders A. Rumination and Related Constructs: Causes, Consequences, and Treatment of Thinking Too Much. Elsevier Academic Press. (2020). doi: 10.1016/B978-0-12-812545-8.00009-7

55. Uddin LQ. Salience Processing and Insular Cortical Function and Dysfunction. Nat Rev Neurosci (2014) 16:55-61. doi: 10.1038/nrn3857

56. Kerns JG, Cohen JD, MacDonald AWIII, Cho RY, Stenger VA, Carter CS. Anterior Cingulate Conflict Monitoring and Adjustments in Control. Science (2004) 303:1023-6. doi: 10.1126/science. 1089910

57. Ridderinkhof KR, Ullsperger M, Crone EA, Nieuwenhuis S. The Role of the Medial Frontal Cortex in Cognitive Control. Science (2004) 306:443-7. doi: $10.1126 /$ science. 1100301

58. Thayer JF, Hansen AL, Saus-Rose E, Johnsen BH. Heart Rate Variability, Prefrontal Neural Function and Cognitive Performance: The Neurovisceral Integration Perspective on Self-Regulation, Adaptation and Health. Ann Behav Med (2009) 37:141-53. doi: 10.1007/s12160-009-9101-z

59. Critchley HD, Eccles J, Garfinkel SN. Interaction Between Cognition, Emotion, and the Autonomic Nervous System. In: RM Buijs, DF Swaab, editors. Handbook of Clinical Neurology, Vol. 117, Autonomic Nervous System. Elsevier B.V (2013). p. 59-77. doi: 10.1016/B978-0-444-53491-0.00006-7

60. Uddin LQ, Nomi JS, Hébert-Seropian B, Ghaziri J, Boucher O. Structure and Function of the Human Insula. J Clin Neurophysiol (2017) 34:300-6. doi: 10.1097/Wnp.0000000000000377

61. Almutairi B, Langley C, Crawley E, Thai N-J. Using Structural and Functional MRI as a Neuroimaging Technique to Investigate Chronic Fatigue Syndrome/ 
Myalgic Encephalopathy: A Systematic Review. BMJ Open (2020) 10:e031672. doi: 10.1136/bmjopen-2019-031672

62. Hampson JP, Zick SM, Khabir T, Wright BD, Harris RE. Altered Resting Brain Connectivity in Persistent Cancer Related Fatigue. NeuroImage: Clin (2015) 8:305-13. doi: 10.1016/j.nicl.2015.04.022

63. Wortinger LA, Glenne Øie MG, Sevenius A, Bruun Wyller V. Aberrant Resting-State Functional Connectivity in the Salience Network of Adolescent Chronic Fatigue Syndrome. PloS One (2016) 11:1-16, e0159351. doi: 10.1371/ journal.pone.0159351

64. Ellard KK, Zimmerman JP, Kaur N, Van Dijk KRA, Roffman JL, Nierenberg AA, et al. Functional Connectivity Between Anterior Insula and Key Nodes of Frontoparietal Executive Control and Salience Networks Distinguish Bipolar Depression From Unipolar Depression and Healthy Control Subjects. Biol Psychiatry: Cogn Neurosci Neuroimaging (2018) 3:473-84. doi: 10.1016/ j.bpsc.2018.01.013

65. Kandilarova S, Stoyanov D, Kostianev S, Specht K. Altered Resting State Effective Connectivity of Anterior Insula in Depression. Front Psychiatry (2018) 9:83. doi: 10.3389/fpsyt.2018.00083

66. Maksoud R, du Preez S, Eaton-Fitch N, Thapaliya K, Barnden L, Cabanas H, et al. A Systematic Review of Neurological Impairments in Myalgic Encephalomyelitis/ Chronic Fatigue Syndrome Using Neuroimaging Techniques. PloS One (2020) 15 (4):e0232475. doi: 10.1371/journal.pone.0232475

67. Mulders PC, van Eijndhoven PF, Schene AH, Beckmann CF, Tendolkar I. Resting-State Functional, Connectivity in Major Depressive Disorder: A Review. Neurosci Biobehav Rev (2015) 56:330-44. doi: 10.1016/j.neubiorev.2015.07.014

68. Knyazev GG, Savostyanov AN, Bocharov AV, Brak IV, Osipov EA, Filimonova, et al. Task-Positive and Task-Negative Networks in Major Depressive Disorder: A Combined fMRI and EEG Study. J Affect Disord (2018) 235:211-9. doi: 10.1016/j.jad.2018.04.003

69. Shan YS, Finegan K, Bhuta S, Ireland T, Staines DR, Marshall-Gradisnik SM, et al. Decreased Connectivity and Increased Blood Oxygenation Level Dependent Complexity in the Default Mode Network in Individuals With Chronic Fatigue Syndrome. Brain Connect (2018) 8:33-9. doi: 10.1089/brain.2017.0549

70. Manca R, Khanb K, Mitoloc M, De Marcoa M, Grievesond L, Varleye R, et al. Modulatory Effects of Cognitive Exertion on Regional Functional Connectivity of the Salience Network in Women With ME/CFS: A Pilot Study. J Neurol Sci (2021) 422:117326. doi: 10.1016/j.jns.2021.117326

71. Askren MK, Jung M, Berman MG, Zhang M, Therrien B, Peltier S, et al. Neuromarkers of Fatigue and Cognitive Complaints Following Chemotherapy for Breast Cancer: A Prospective fMRI Investigation. Breast Cancer Res Treat (2014) 147:445-55. doi: 10.1007/s10549-014-3092-6

72. Jung MS, Zhang M, Askren MK, Berman MG, Peltier S, Hayes DF, et al. Cognitive Dysfunction and Symptom Burden in Women Treated for Breast Cancer: A Prospective Behavioral and fMRI Analysis. Brain Imaging Behav (2016) 11:86-97. doi: 10.1007/s11682-016-9507-8

73. de Dreu MJ, Schouwenaars IT, Ruttena GJM, Ramsey NF, Jansma JM. Fatigue in Brain Tumor Patients, Towards a Neuronal Biomarker. NeuroImage: Clin (2020) 28:102406. doi: 10.1016/j.nicl.2020.102406

74. Menning S, de Ruiter MB, Veltman DJ, Koppelmans V, Kirschbaum C, Boogerd W, et al. Multimodal MRI and Cognitive Function in Patients With Breast Cancer Prior to Adjuvant Treatment - The Role of Fatigue. NeuroImage: Clin (2015) 7:547-54. doi: 10.1016/j.nicl.2015.02.005

75. Menning S, de Ruiter MB, Veltman DJ, Booger W, Oldenburg HSA, Reneman $\mathrm{L}$, et al. Changes in Brain Activation in Breast Cancer Patients Depend on Cognitive Domain and Treatment Type. PloS One (2017) 12:e0171724. doi: 10.1371/journal.pone. 0171724

76. Churchill NW, Cimprich B, Askren MK, Reuter-Lorenz PA, Jung MS, Peltier $S$, et al. Scale-Free Brain Dynamics Under Physical and Psychological Distress: Pre-Treatment Effects in Women Diagnosed With Breast Cancer. Hum Brain Mapp (2015) 36:1077-92. doi: 10.1002/hbm.22687

77. Hawco C, Laagishan Y, Aristotle N, Voineskos AN, Lyon R, Tan T, et al. Greater Individual Variability in Functional Brain Activity During Working Memory Performance in Young People With Autism and Executive Function Impairment. NeuroImage Clin (2020) 27:102260. doi: 10.1016/j.nicl.2020.102260

78. McDonald BC, Conroy SK, Ahles TA, West JD, Saykin AJ. Alterations in Brain Activation During Working Memory Processing Associated With Breast Cancer and Treatment: A Prospective Functional Magnetic Resonance Imaging Study. J Clin Oncol (2012) 30:2500-8. doi: 10.1200/JCO.2011.38.5674
79. Tomas C, Brown A, Strassheim V, Elson JL, Newton J, Manning P. Correction: Cellular Bioenergetics Is Impaired in Patients With Chronic Fatigue Syndrome. PloS One (2018) 13(2):e0192817. doi: 10.1371/journal.pone.0192817

80. de Lange FP, Kalkman JS, Bleijenberg G, Hagoort P, van der Meer JWM, Toni Y, et al. Gray Matter Volume Reduction in the Chronic Fatigue Syndrome. Neuroimage (2005) 26:777-81. doi: 10.1016/j.neuroimage.2005.02.037

81. Cook DB, O'Connor PJ, Lange G, Steffener J. Functional Neuroimaging Correlates of Mental Fatigue Induced by Cognition Among Chronic Fatigue Syndrome Patients and Controls. Neuroimage (2007) 36:108-22. doi: 10.1016/ j.neuroimage.2007.02.033

82. Mizuno K, Tanaka M, Tanabe HC, Jouboi T, Kawatani J, Shigihara Y, et al. Less Efficient and Costly Processes of Frontal Cortex in Childhood Chronic Fatigue Syndrome. NeuroImage Clin (2015) 9:355-68. doi: 10.1016/ j.nicl.2015.09.001

83. Inagaki M, Yoshikawa E, Matsuoka Y, Sugawara Y, Nakano T, Akechi T, et al. Smaller Regional Volumes of Brain Gray and White Matter Demonstrated in Breast Cancer Survivors Exposed to Adjuvant Chemotherapy. Cancer (2007) 109:146-56. doi: $10.1002 / \mathrm{cncr} .22368$

84. McDonald BC, Saykin AJ. Alterations in Brain Structure Related to Breast Cancer and its Treatment: Chemotherapy and Other Considerations. Brain Imaging Behav (2013) 7:374-87. doi: 10.1007/s11682-013-9256-x

85. Christoff K, Gordon AM, Smallwood J, Smith R, Schooler JW, et al. Experience Sampling During fMRI Reveals Default Network and Executive System Contributions to Mind Wandering. Proc Natl Acad Sci (2009) 106:8719-24. doi: 10.1073/pnas.0900234106

86. Hampson M, Driesen N, Roth JK, Gore JC, Constable RT. Functional Connectivity Between Task-Positive and Task-Negative Brain Areas and its Relation to Working Memory Performance. Magnetic Resonance Imaging (2010) 28:1051-7. doi: 10.1016/j.mri.2010.03.021

87. Kelly AC, Uddin LQ, Biswal BB, Castellanos FX, Milham MP. Competition Between Functional Brain Networks Mediates Behavioral Variability. Neuroimage (2008) 39:527-37. doi: 10.1016/j.neuroimage.2007.08.008

88. Radel R, Brisswalter J, Perrey S. Saving Mental Effort to Maintain Physical Effort: A Shift of Activity Within the Prefrontal Cortex in Anticipation of Prolonged Exercise. Cognit Affect Behav Neurosci (2017) 17:305-14. doi: 10.3758/s13415-016-0480-x

89. Andreotti C, Root JC, Ahles TA, McEwen BS, Compas BE. Cancer, Coping, and Cognition: A Model for the Role of Stress Reactivity in Cancer-Related Cognitive Decline. Psycho-Oncology (2014) 24:617-23. doi: 10.1002/pon

90. Brosschot JF, Piepera S, Thayer JF. Expanding Stress Theory: Prolonged Activation and Perseverative Cognition. Psychoneuroendocrinology (2005) 30:1043-9. doi: 10.1016/j.psyneuen.2005.04.008

91. Penner K, Rausch M, Kappos L, Opwis K, Radü EW. Analysis of Impairment Related Functional Architecture in MS Patients During Performance of Different Attention Tasks. J Neurol (2003) 250:461-72. doi: 10.1007/s00415003-1025-0

92. Carey RN, Connell LE, Johnston M, Rothman AJ, de Bruin M, Kelly MP, et al. Behavior Change Techniques and Their Mechanisms of Action: A Synthesis of Links Described in Published Intervention Literature. Annal Behav Med (2019) 53:693-707. doi: 10.1093/abm/kay078

93. Finne E, Glausch M, Exner A-K, Sauzet O, Stölzel F, Seidel N. Behavior Change Techniques for Increasing Physical Activity in Cancer Survivors: A Systematic Review and Meta-Analysis of Randomized Controlled Trials. Cancer Manage Res (2018) 10:5125-43. doi: 10.2147/CMAR.S170064

94. Kurniawan IT, Guitart-Masip M, Dolan RJ. Dopamine and Effort-Based Decision Making. Front Neurosci (2011) 5:81. doi: 10.3389/fnins.2011.00081

95. Miller AH, Jones JF, Drake DF, Tian H, Unger ER, Pagnoni G. Decreased Basal Ganglia Activation in Subjects With Chronic Fatigue Syndrome: Association With Symptoms of Fatigue. PloS One (2014) 23;9(5):e98156. doi: 10.1371/journal.pone.0098156

Conflict of Interest: The authors declare that the research was conducted in the absence of any commercial or financial relationships that could be construed as a potential conflict of interest.

Publisher's Note: All claims expressed in this article are solely those of the authors and do not necessarily represent those of their affiliated organizations, or those of the publisher, the editors and the reviewers. Any product that may be evaluated in 
this article, or claim that may be made by its manufacturer, is not guaranteed or endorsed by the publisher.

Copyright (c) 2021 André, Gastinger and Rébillard. This is an open-access article distributed under the terms of the Creative Commons Attribution License
(CC BY). The use, distribution or reproduction in other forums is permitted, provided the original author(s) and the copyright owner(s) are credited and that the original publication in this journal is cited, in accordance with accepted academic practice. No use, distribution or reproduction is permitted which does not comply with these terms. 